\title{
REPUBLICANISMO E INDEPENDÊNCIA DO BRASIL NA “CONSPIRAÇÃO SOCIALISTA NA BAHIA EM 1798” DE FRANCISCO ADOLPHO DE VARNHAGEN
}

\author{
REPUBLICANISM AND BRAZILIAN INDEPENDENCE IN FRANCISCO \\ ADOLPHO DE VARNHAGEN'S "CONSPIRAÇÃO SOCIALISTA NA BAHIA EM \\ 1798"
}

\author{
Patrícia Valim \\ PPGH/UFBA/UFOP \\ Orcid: 0000-0002-7615-1142
}

\begin{abstract}
Resumo: As lutas pela independência política do Brasil nas várias províncias e o intenso debate político da época explicitaram que um projeto de nação republicana era uma forte e constante possibilidade histórica, de maneira que os republicanismos mobilizados em vários movimentos sociais desde o final do século XVIII foram constantemente criminalizados em várias esferas pela política d. Pedro I e d. Pedro II. O objetivo deste artigo é demonstrar a maneira pela qual essa criminalização ocorreu no processo de escrita da história de Francisco Adolpho de Varnhagen sobre a Conjuração Baiana de 1798, explicitando que apenas homens dos mais baixos setores daquela sociedade eram adeptos ao projeto de uma nação republicana, razão pela qual o autor enalteceu em sua obra como a coroa portuguesa afastou esses setores do universo da político com a punição exemplar dos réus da Conjuração Baiana, enforcados e esquartejados em praça pública em 1799.
\end{abstract}

\footnotetext{
Abstract: The struggles for the political independence of Brazil in the various provinces and the intense political debate at the time made it clear that a project for a republican nation was a strong and constant historical possibility, so that the republicanisms mobilized in various social movements since the end of the 18th century were constantly criminalized in various spheres by politics d. Peter I and d. Peter II. The purpose of this article is to demonstrate the way in which this criminalization occurred in the process of writing the story of Francisco Adolpho de Varnhagen on the Bahia Conjuration of 1798, explaining that only men from the lowest sectors of that society were adept at the project of a republican nation, which is why the author praised in his work how the Portuguese crown removed these sectors from the world of politics with the exemplary punishment of the defendants of the Conjuração Baiana, hanged and quartered in a public square in 1799.
} 
Por ocasião das comemorações dos 130 anos da Proclamação da República no Brasil, a história da polissemia do conceito de República foi objeto de análise de pesquisadores em uma das principais publicações sobre o tema: "Dicionário da República: 51 textos críticos", organizado pelas historiadoras Lilia M. Schwarcz e Heloísa M. Starling. Na introdução da publicação, as autoras chamam atenção para o fato de que até hoje persiste entre nós, população brasileira, um mal-estar permanente em razão de um projeto de nação republicana ser algo irrealizável, fadado ao fracasso, pois:

"em uma sociedade de raiz escravista como a brasileira, de passado colonial, de economia aberta, monocultura e de exportação, historicamente violenta $e$ autoritária, ainda hoje por demais desigual, o caminho para a construção democrática e republicana não tem sido apenas volátil; tem sido tortuoso, marcado por linhas quebradas e reentrâncias, feito com pontos altos de otimismo democrático e baixos de inversão antidemocrática."

Para além dessa herança do passado brasileiro constantemente ressignificado, sem ser superado, sobretudo em momentos de efemérides, as autoras propõem como resposta a esse mal-estar a busca dos princípios e da história do conceito de República, sobretudo a partir do momento em que o termo surge em contraposição à natural desigualdade entre os homens, principal fundamento da sociedade de Antigo Regime, ligando-se à valorização da política, da participação do cidadão comum na vida pública, dos direitos, da igualdade, da liberdade. $^{2}$

Na história do Brasil, esse momento ocorre durante a conflituosa transição do século XVIII para o século XIX, quando as revoltas e motins se desdobraram em inconfidência e conjuração porque seus partícipes começaram a questionar a autoridade régia, os privilégios, os termos da dominação colonial e reivindicaram o princípio de isonomia para ascensão na carreira militar e o direito de participar da vida política. ${ }^{3}$

Não foi por outra razão que, a partir desse momento, os funcionários régios da Coroa Portuguesa passaram a associar o termo República aos "abomináveis princípios franceses"

\footnotetext{
${ }^{1}$ SCHWARCZ, Lilia M.; STARLING, Heloísa M (Orgs.). Dicionário da República: 51 textos críticos. São Paulo: Companhia das Letras, 2019, p. 17.

${ }^{2}$ Idem.

${ }^{3}$ Ler, sobretudo, ATTALAH, Cláudia Cristina Azeredo. Da justiça em nome d'El Rey: justiça, ouvidores e inconfidência no centro-sul da América Portuguesa. Rio de Janeiro: EdUERJ, 2015; FIGUEIREDO, Luciano Raposo de Almeida. O Império em apuros: notas para o estudo das alterações ultramarinas e das práticas do Império colonial português, séculos XVII e XVIII. In: Júnia Ferreira Furtado (Org.). Diálogos Oceânicos. Minas Gerais e as novas abordagens para uma história do Império Ultramarino Português. Belo Horizonte: Editora UFMG, 2001, pp. 483-518; RAMOS, Rui. República - Republicanos. Ler História [Online], 55 | 2008, posto online no dia 16 outubro 2016, consultado no dia 28 junho 2020; VALIM, Patrícia. Conjuração Baiana e República Bahinense. In: Lilia M. Schwarcz; Heloísa M. Starling (Org.). Dicionário da República. 1ed.São Paulo: Companhia das Letras, 2019, v. 1, p. 53-59.
} 
para designar e deslegitimar um conjunto de leis francesas que garantiriam um governo de iguais, ainda que a ideia de igualdade formulada pelos homens do tempo ido no Brasil aparecesse balizada pelos limites impostos pelo escravismo como ordenador daquela sociedade. ${ }^{4}$ No ensaio sedicioso da Sociedade Literária do Rio de Janeiro, por exemplo, 1794, Silva Alvarenga afirmou: "não há melhor governo do que o governo de iguais desde que restrito aos iguais". 5

O historiador Kenneth Maxwell demonstra que, em 1789, o modelo de governo imaginado pelos revoltosos da chamada Inconfidência Mineira foi o da República Constitucional, inspirado no conjunto documental sobre a Independência Americana "Recueil des Loix Constitutives des États-Unis de l'Amérique". Embora os mineiros tivessem avançado sobre o regime de representação política e entre eles houvesse quem cogitasse a libertação dos escravos para lutar pela causa, a maioria dos conspiradores eram escravistas e achavam isso um perigo e um desastre, pois não haveria "ninguém para trabalhar nas minas". ${ }^{6}$

Também na Conjuração Baiana de 1798, em um dos boletins manuscritos afixados em locais públicos da cidade de Salvador, os "Anônimos Republicanos" anunciaram os termos da República projetada: "animai-vos, povo bahinense, que está para chegar o tempo feliz da liberdade. O tempo em que todos seremos irmãos, todos seremos iguais”. Durante um interrogatório, o acusado Luiz Gonzaga das Virgens e Veiga esclareceu o entendimento de igualdade ao afirmar que "se tinha ouvido falar em uma conspiração [...] para o fim de fazer um levantamento e por ele se estabelecer um governo de igualdade, onde entrassem brancos, pardos e negros, sem distinção de cor e só sim de capacidade". A igualdade surge mediada pela capacidade, pelo mérito como resposta à demanda dos milicianos por isonomia nos critérios de ascensão aos postos da carreira militar. ${ }^{7}$ Mas ainda assim é preciso destacar que aqueles homens do tempo ido foram violentamente reprimidos porque discutiram liberdade, igualdade e república nas ruas da cidade. ${ }^{8}$

Marcello Basile chama atenção para a insubmissão crescente dessas manifestações públicas com o domínio da linguagem republicana para criticar o despotismo e as instituições monárquicas ao tempo em que passaram a reivindicar as liberdades de imprensa e de culto,

\footnotetext{
${ }^{4}$ FERES JÚNIOR, João. Léxico da História dos Conceitos Políticos do Brasil. Belo Horizonte/São Paulo: EdUFMG/Humanitas, 2014; NEVES, Lúcia Maria B. Pereira das. O medo dos abomináveis princípios franceses: a censura dos livros nos inícios do século XIX. In: Acervo: Revista do Arquivo Nacional. - Vol. 4, no 1 (1989), p. 113-119.

${ }^{5}$ STARLING, Heloísa M. e LYNCH, Christian Edward Cyril. República/Republicanos. In: FERES JÚNIOR, João. Op.cit., p. 227.

${ }^{6}$ MAXWELL, Kenneth (Org.). O livro de Tiradentes: Transmissão atlântica de ideias políticas no século XVIII. São Paulo: Penguin Classics/Companhia das Letras, 2013.

${ }^{7}$ VALIM, Patrícia. Conjuração Baiana 1798 e República Bahinense. In: Lilia M. Schwarcz; Heloísa M. Starling (Org.). Dicionário da República. São Paulo: Companhia das Letras, 2019, v. 1, pp. 53-59.

${ }^{8}$ VALIM, Patrícia. Da contestação à conversão: a punição exemplar dos réus da Conjuração Baiana de 1798. Topoi (Rio de Janeiro), v. 10, p. 14-23, 2009.
} 
os direitos de cidadania de índios, negros e mulatos, o fim gradual da escravidão, a soberania do povo e o direito de resistência à tirania. Para o autor, a combinação desses elementos remetia às diversas matrizes da tradição republicana, radicalizada pela defesa de uma postura cívica de todos os setores da sociedade por Frei Caneca (1779-1825) na Insurreição de Pernambucano de $1817 .{ }^{9}$ As lutas e o intenso debate político da época explicitaram que um projeto de nação republicana era uma forte e constante possibilidade histórica a ser combatida pelos arautos da monarquia constitucional centralizadora. Marcelo Cheche Galvez demonstra que, por ocasião da Confederação do Equador (1824), a centralidade da fidelidade política a d. Pedro I fez com que seus críticos e adversários políticos fossem desqualificados na imprensa da corte como "republicanos a serviço da instauração da desordem". ${ }^{10}$

Para Lúcia Maria Pereira Bastos Neves, por ocasião dos chamados "panfletos de circunstâncias", ${ }^{11}$ o republicanismo contido na palavra "república", frequentemente mobilizada para legitimar as lutas pela Independência e a ruptura política do Brasil com Portugal passou a ser criminalizado em razão do termo: "o bom governo de bons cidadãos" com a valorização do bem comum acima de interesses individuais tão caro ao universo do Antigo Regime. Isso significou não só um intenso debate sobre quem era cidadão no novo Estado do Brasil durante a Constituinte de 1823, como após a Constituição Outorgada de 1824 a população considerada insubmissa passou a reivindicar o direito de fazer política ${ }^{12}$ como criticar a própria constituição, o Poder Moderador, o Senado Vitalício, os valores aristocráticos ao tempo em que discutiam o federalismo, a democracia e os termos de uma nação republicana.

Não foi por outra razão que o republicanismo e o projeto de nação republicana foram constantemente criminalizados em várias frentes pela política d. Pedro I e d. Pedro II. O objetivo deste artigo é demonstrar a maneira pela qual essa criminalização ocorreu no processo de escrita da história de Francisco Adolpho de Varnhagen sobre a Conjuração Baiana de 1798, para demonstrar a um só tempo que apenas homens dos mais baixos setores daquela sociedade desejavam uma nação republicana por ocasião da Independência do Brasil e como a coroa portuguesa afastou esses setores do universo da político com a punição exemplar dos réus do movimento, enforcados e esquartejados em praça pública em 1799.

\footnotetext{
${ }^{9}$ BASILLE, Marcelo. Imprensa Republicana no Brasil [XIX]. In: Lilia M. Schwarcz; Heloísa M. Starling (Org.). Dicionário da República. São Paulo: Companhia das Letras, 2019, pp. 156-162.

${ }^{10}$ GALVES, Marcelo Cheche. O público sincero e imparcial: imprensa e independência do Maranhão (18211826). Tese de Doutoramento, PPGH/UFF, 2010, pp.228.

${ }^{11}$ NEVES, Lucia Maria Bastos Pereira das. Corcundas e Constitucionais: a cultura política da Independência (1820-1822). Rio de Janeiro: Revan, FAPERJ, 2003.

12 VALIM, Patrícia. Um crescendo de tomada de consciência: a Conjuração Baiana de 1798 no primeiro centenário da Independência do Brasil. Rio de Janeiro, Intellèctus, ano XIX, n. 1, 2020, p. 141-176
} 
Francisco Adolfo de Varnhagen, Visconde de Porto Seguro, nasceu na cidade de Sorocaba, então província de São Paulo, em 17 de fevereiro de 1816, filho do Sargento-Mor do Real Corpo de Engenheiros Frederico Luiz Guilherme de Varnhagen e de sua mulher D. Maria Flavia de Sá Magalhães. Seu pai era engenheiro militar, com boa formação técnica, prestando serviços à Coroa Portuguesa na fábrica de ferro de Figueiró dos Vinhos, quando voltou para o Brasil, convocado por d. Rodrigo de Souza Coutinho, para trabalhar na fábrica de ferro de Ipanema. ${ }^{13}$

Varnhagen permaneceu em Sorocaba por sete anos, transferindo-se com sua família para Portugal em 1823. Cursou seus primeiros estudos no Real Colégio Militar da Luz, matriculando-se, em seguida, na Academia da Marinha. Foi aluno do Colégio dos Nobres e cursou a Academia de Fortificações, titulando-se engenheiro, em 1834. Com pretensões historiográficas, Varnhagen submete seu trabalho "As reflexões críticas sobre um texto de Gabriel Soares de Sousa”, publicado em 1839, à Academia Real das Ciências de Lisboa. Aos 24 anos, licenciou-se do exército português e retornou ao Brasil, pleiteando a nacionalidade brasileira ao governo imperial, que lhe foi concedida por decreto, em 24 de setembro de 1844. ${ }^{14}$ Contando com a relevante indicação de Antonio Meneses Vasconcelos de Drumond, ministro plenipotenciário do Império em Lisboa, Varnhagen foi admitido como sócio-correspondente do Instituto Histórico e Geográfico Brasileiro, por decreto de 1840, cinco dias antes do golpe da Maioridade que encerrou o período regencial.

Em 1842, foi nomeado Oficial do Imperial Corpo de Engenheiros, do qual mais tarde pediu demissão para seguir a carreira diplomática. Em 1851 já era encarregado dos negócios de Madrid, servindo missão junto às Repúblicas do Pacífico e à Corte de Viena, e elegeu-se primeiro-secretário do IHGB. ${ }^{15}$ A partir daí, conforme seus biógrafos, Varnhagen desempenhou relevantes serviços junto às missões da Península Ibérica das décadas de 1840-

\footnotetext{
${ }^{13}$ São vários os biógrafos de Francisco Adolfo de Varnhagen. Ler, entre outros: Hans Jürgen Wilhem Horsch. Francisco Adolfo de Varnhagen: subsídios para uma bibliografia (1816-1878). São Paulo: Unidas, 1982; Orlando de Carvalho Damasceno. Ligeiro esboço biográfico de Francisco Adolfo de Varnhagen: primeiro e último Visconde de Porto Seguro. Separata da Revista do Arquivo Municipal de São Paulo, n. 126, Departamento de Cultura, Divisão do Arquivo Histórico, 1949; José Honório Rodrigues. Varnhagen, mestre da história geral do Brasil. RIHGB, vol. 275, 1967, pp. 170-196; Clado Ribeiro Lessa. Vida e obra de Varnhagen. RIHGB, n. 224, 1954; Francisco Iglesias. Historiadores do Brasil: capítulos da historiografia brasileira. São Paulo/Belo Horizonte: Nova Fronteira/ Ed. Da UFMG; Capistrano de Abreu. Sobre o Visconde de Porto Seguro. Ensaios e Estudos (Crítica e História). Rio de Janeiro/Brasília: Civilização Brasileira/INL, $1^{\mathrm{a}}$. série, $2^{\mathrm{a}}$. edição, 1975.

${ }^{14}$ Cf. Lúcia Maria Paschoal Guimarães. Op. cit., p. 77; Temístocles Américo Corrêa Cezar. Varnhagen: um historiador entre a Europa e o Novo Mundo: ensaio sobre o conceito de história no Brasil do século XIX. Texto traduzido e gentilmente cedido pelo autor, que integra a tese de doutoramento L'écriture de l'histoire au Brésil au XIX siècle. Essai sur une rhétorique de la nationalité. Le cas Varnhagen. Paris, Ecóle des Hautes Etudes en Sciences Sociales, EHESS, França, 2002, II tomos.

${ }^{15}$ Cf. A Missão Varnhagen nas Repúblicas do Pacífico: 1863 a 1867. Centro de História e Documentação Diplomática, Rio de Janeiro/Brasília: CDHH/FUNAG, 2005; Sacramernto Blake. Diccionario Bibliographico Brazileiro. Tomo II, p. 371.Lisboa: Edições Afrontamento.
} 
1850, às missões americanas de 1859-1867 e ao Império austro-húngaro em 1868-1878. ${ }^{16} \mathrm{~A}$ par disso, como primeiro-secretário, Varnhagen passou a ter contato direto com Pedro II, que frequentava assiduamente as sessões da agremiação. Organizou a biblioteca da agremiação, compilou e organizou documentos sobre o Brasil; na maioria das vezes, dispersos nas províncias e nos arquivos portugueses e espanhóis.

Pelo reconhecimento de seus méritos diplomáticos e históricos, Pedro II concedeulhe o título de Barão de Porto Seguro, em 1871, e Visconde, com honras de grandeza do mesmo título, em 1874. ${ }^{17}$ Regressando a Viena, após uma viagem para a coleta de documentos em São Paulo, Goiás e Bahia, Varnhagen faleceu em 1878. Francisco Adolfo de Varnhagen foi grande no Império: Comendador da Ordem Imperial da Rosa, Cavaleiro da Imperial Ordem de Cristo, Grã-Cruz da Ordem de Santo Estanislau - da Rússia, da Coroa de Ferro da Áustria, de Isabel, a Católica, de Espanha, e de Carlos III, também da Espanha. Participou como sócio correspondente de várias academias congêneres; e deixou extensa e variada obra, composta por livros, opúsculos, artigos e memórias. ${ }^{18}$ Mas Varnhagen nobilitou-se na cena historiográfica nacional, sobretudo, pela obra História Geral do Brasil da sua separação e independência de Portugal.

A edição de lançamento do primeiro volume de História Geral do Brasil de Varnhagen foi em Madrid, em 1854. ${ }^{19}$ A primeira edição é composta de 54 secções ou capítulos, encadeados no conjunto geral da obra de acordo com a cronologia evolutiva e linear dos acontecimentos dos tempos coloniais. Assim, os acontecimentos históricos são narrados por um continuum da colonização portuguesa, que se inicia com o Brasil sendo concebido como uma herança do Tratado de Tordesilhas, após a partilha do novo mundo entre a dinastia de Avis e Castela, e termina com a chegada da família real portuguesa no Rio de Janeiro, em 1808. Entre o início da colonização portuguesa, com a chegada da esquadra de Cabral no litoral americano, e a chegada dos Braganças no Rio de Janeiro, a história de Varnhagen consagrou a monarquia constitucional como regime ideal, louvou a dinastia bragantina, buscou no plano interno elementos comuns que assegurassem a

\footnotetext{
${ }^{16}$ A Missão..., op.cit., p. 9.

17 Maria Lúcia Paschoal Guimarães, Francisco Adolfo de Varnhagen..., op.cit.; Manuel Luís Salgado Guimarães, op.cit.; Arno Wehling, op.cit.; Clado R. Lessa, op.cit.; José Honório Rodrigues, op.cit.; Temístocles Cezar, op.cit.

${ }^{18}$ Cf. Armando Ortega Fontes. Bibliografia de Varnhagen. Rio de Janeiro: Ministério das Relações Exteriores, 1945.

${ }^{19}$ A $2^{\mathrm{a}}$. edição revista e ampliada pelo autor continha 1200 páginas e foi lançada em 1871 , com alteração na disposição dos dez primeiros capítulos. A $3^{\text {a }}$. edição, datada de 1906, revista por Capistrano de Abreu, corresponde apenas à terça parte da obra original, devido a um incêndio na oficina impressora. As edições subsequentes foram revistadas e anotadas por Rodolfo Garcia, nas quais há a incorporação das notas de Capistrano de Abreu e do próprio Varnhagen. Veja-se a esse respeito: Maria Lúcia Paschoal Guimarães. Francisco Adolfo Varnhagen: História Geral do Brasil. Op.cit., p. 79. Para a análise da revolta baiana de 1798 na obra de Varnhagen, a edição utilizada nesta pesquisa é História Geral do Brasil. 10a . edição integral, Belo Horizonte/São Paulo: Itatiaia/Edusp, 1981, comparando-a com a primeira edição da obra, uma vez que entra a primeira edição e a que utilizamos manteve-se as alterações do autor para a publicação da segunda edição.
} 
identidade nacional, e, no plano externo, a identidade brasileira foi pensada, sobretudo, em oposição às nações republicanas. ${ }^{20}$

Nessa perspectiva, foi desqualificando o significado das ideias republicanas no item Voltaire. A Hespanha atrozmente contra Portugal, no período de regência de d. João VI, na penúltima seção da primeira edição de História Geral do Brasil, que Varnhagen versou sobre a revolta baiana de 1798. No item "Pazes. Conspiração socialista na Bahia em 1798",21 Varnhagen afirma que

"antes de passar adiante, cumpre referir que as chamas incendiárias da revolução francesa não deixaram de saltar ao Brazil, apezar da distância, e na Bahia se chegou quase a atear, pelas suas labaredas, em agosto de 1798, um incêndio, que foi dias antes prevenido". ${ }^{22}$

Para Varnhagen,

"se a conspiração de Minas, tão patriótica em seus fins, tão nobre em seus agentes, e tão habilmente premeditada, julgamos que foi um bem que se mallograsse, com muito mais razão agradeçamos (sic) a Deus o haver-nos amparado a tempo contra est'outra, com tendências mais socialistas que políticas, como arremedo que era das scenas de horror que a França, e principalmente a bella ilha de S. Domingos, acabavam de presenciar (...),"23

Como a revolta baiana de 1798 fora embalada "ao santo grito de liberdade, igualdade e fraternidade", Varnhagen afirma que os partícipes se esqueceram que em uma província

"com tanta escravatura, [caso] a sua generosidade lograsse triunfo, libertando a todos os escravos, como promettiam, depressa, como se viu no Haity, seriam victimas destes desenfreados e em muitíssimo maior número". ${ }^{24}$

Após desqualificar a revolta pela influência dos princípios da Revolução Francesa, Varnhagen passa a descrever os partícipes da revolta baiana. No item da primeira edição, "Seus Cabeças. Ridículos pasquins e plebiscitos.", o autor afirma que os conspiradores que se chegaram a descobrir "não subiam a quarenta, nenhum deles homem de talento e de

\footnotetext{
${ }^{20}$ Cf. Manoel Luís Salgado Guimarães. Usos da História: refletindo sobre identidade e sentido. In: História em Revista, Dossiê Historiografia, vol 6, 2000, pp. 21-36.

${ }^{21}$ Arquivo Histórico do Itamaraty, doravante AHI, códices 351-360, Lata 351, doc. A. A documentação analisada é a primeira edição de Varnhagen com anotações e alterações manuscritas pelo próprio autor para a publicação da segunda edição, em 1871.

${ }^{22}$ Idem, p. 292.

${ }^{23}$ Idem.

${ }^{24}$ Idem, ibidem.
} 


\section{Patricia Valim}

Republicanismo e independência do Brasil na "conspiração socialista na bahia em 1798" de Francisco Adolpho de

Varnhagen

Dossier Historia del Brasil colonial: de las raíces históricas

al proceso de concienciación y crisis (siglos XVI-XIX)

Número 47, diciembre 2021, pp. 5-20

DOI: https://dx.doi.org/10.12795/Temas-Americanistas.2021.i47.02

consideração; e quase todos libertos ou escravos, pela maior parte pardos". Para o Visconde "a pouca valia dos revolucionários se deduz do modo estranho como projectaram levar à execução os seus planos". Varnhagen afirma que a partir

"da leitura attenta dos depoimentos e autos das devassas, ${ }^{25}$ etc., se reconhece que a conspiração na Bahia não tinha chefe: e quando muito poderemos considerar como seus coripheus o alfaiate João de Deus do Nascimento, cabo d'esquadra de milícias, e os soldados Lucas Dantas e Luiz Gonzaga das Virgens. Tinha este 36 annos de idade, e aquelles, um 28, e outro 24 ". ${ }^{26}$

Apesar da consulta à documentação, chama atenção o fato de Varnhagen não citar, neste ponto, Manuel Faustino dos Santos Lira, um dos réus enforcados em praça pública, ${ }^{27}$ como um dos participantes ou "coripheu" da "conspiração" na Bahia. A par disso, a narrativa do Visconde sobre a revolta baiana de 1798 descreve, pela primeira vez, o conteúdo veiculado pelos pasquins afixados pelos partícipes em locais públicos da Salvador, na manhã de 12 de agosto de 1798. Afirma que "de parte destes escriptos [pasquins] possuímos cópias autênticas e nos inspiram lástima". Neste ponto da narrativa, Varnhagen cita minuciosamente os termos dos pasquins, afirmando que "por conseqüência da liberdade eram seiscentos e setenta e seis [partícipes]", que o soldado "perseba 200 reis de soldo cada dia", que a "liberdade consiste no estado feliz, no estado livre do abatimento", que a França "está cada vez mais exaltada [...] o Pontífice já está abandonado e desterrado", e que "os commerciantes e lavradores que teriam todo o direito soubre (sic) as suas fazendas". ${ }^{28}$

Ao referir-se aos pasquins com desdém, o objetivo do autor é o de justificar as ações das autoridades locais perante a "ínfima qualidade" dos conspiradores. Varnhagen inevitavelmente passa a descrever as ações de d. Fernando José de Portugal e Castro, como, por exemplo, "antes de ordenar devassa, e depois de acautelar-se com algumas providencias". As providências tomadas pelo então governador foram, em primeiro lugar, "vendo que a lettra [dos pasquins] não fora disfarçada [...] lembrou-se [d. Fernando] de comparal-a com a dos requerimentos e papéis que havia na secretaria do governo". ${ }^{29}$ Depois de resultar na prisão "em segredo de Domingos da Silva Lisboa, filho de Portugal e alferes de granadeiros de milícias", Varnhagen nos conta que, após o aparecimento de "dois

\footnotetext{
${ }^{25}$ Varnhagen é o primeiro historiador a citar a existência de duas devassas simultâneas acerca da revolta baiana de 1798, bem como o de descrever o conteúdo veiculado nos pasquins sediciosos. Em relação às devassas, Varnhagen afirma e agradece ao marquês de Palma, seu padrinho e amigo, pela documentação. Cf. As anotações de Capistrano de Abreu na nota n. 66 da 10a. edição integral, p. 25. Na primeira edição, Varnhagen limita-se a agradecer ao marquês de Palma pelas cópias autênticas concedidas.

${ }^{26}$ AHI, doc. cit., p. 293.

${ }^{27}$ Cf. As denúncias, as assentadas e os termos de conclusão das devassas citadas nos Autos das Devassas.

${ }^{28}$ AHI, doc. cit., p. 293.

${ }^{29}$ Idem, p. 294.
} 
novos documentos da mesma lettra que os antigos", o governador procedeu a novos exames, resultando destes "a prisão do próprio Luiz Gonzaga das Virgens".

A respeito da prisão de Luiz Gonzaga, para o autor "pode-se dizer que pela sua inabilidade a si próprio confessara pela lettra, além de denunciar a conspiração, publicando-a com loucos avisos e ridículos plebiscitos". ${ }^{30}$ Sobre o aparecimento de dois novos documentos, Varnhagen afirma que

"eram duas cartas; uma para o prior dos Carmelitas descalços futuro geral em chefe da igreja Bahinense, segundo a secção (sic) do Plebiscito de 19 do corrente [1798] - em que ordenava que todos aprovassem a revolução [...]. A outra, encontrada como esta por uma mulher, na igreja do convento do Carmo, no dia 22, era um officio ao governador [...]". 31

Após descrever a carta na qual os partícipes da revolta dão conta de que d. Fernando José de Portugal seria o futuro chefe da "República Bahinense", Varnhagen afirma: "deixando sem comentário este documento, apressemo-nos a declarar que logo depois de ser preso o pardo Luiz Gonzaga, se apresentaram ao governador, para delatar a conspiração, três denunciantes...". Os denunciantes contaram ao governador sobre a reunião do dia 25 de agosto de 1798, no campo do Dique do Desterro, que deu "logar a poderem comprehender em suas denúncias mais alguns infelizes, que todos foram presos antes do dia 28, que era o aprazado".

A narrativa de Varnhagen sobre a revolta baiana de 1798 termina enaltecendo as ações do governador que "havendo resolvido sabiamente [...] prevenir antes o golpe para evitar as desgraças que poderiam succeder se elle se chega a tentar". O Visconde encerra o tema da revolta de 1798, na primeira edição, afirmando que após a coroa portuguesa ter mandado o governador executar a sentença da Relação da Bahia

"subiram no dia 8 de novembro do anno seguinte [1799] ao patíbulo, que se erigiu na praça da Piedade, além dos três mencionados cabeças, o jovem liberto Manuel Faustino, que apenas contava desoito annos". ${ }^{32}$

Entretanto, nas edições ulteriores, o autor termina a interpretação sobre a revolta baiana de 1798 acrescentando a seguinte informação

“com relação talvez ainda a esses sucessos, a carta régia de 8 de junho de 1800 pela qual D. Fernando José de Portugal era nomeado vice-rei do Rio de Janeiro continha algumas palavras referindo-se ao aviso de 24 de julho de 1797; recomendando

\footnotetext{
${ }^{30}$ Idem.

${ }^{31}$ Idem, p. 295.

${ }^{32}$ AHI, doc. cit., p. 295.
} 
vigilância contra os que propagassem doutrinas incendiárias, e acrescenta: sendo evidente que é muito mais acertado prevenir graves ruínas, afastando da sociedade aqueles que as podem produzir do que tolerando-os ao princípio, e expor-se depois a proceder contra eles os mais rigorosos e severos castigos". ${ }^{33}$

A primeira edição da História geral do Brasil, de Francisco Adolfo de Varnhagen, como se sabe, foi muito criticada à época e gerou várias polêmicas entre seus pares do Instituto Histórico e Geográfico Brasileiro. ${ }^{34}$ Nesse rol de polemistas estão, entre outros, nomes como Januário da Cunha Barbosa, Domingos Alves Branco Moniz Barreto, Manuel Antônio de Almeida, Henrique de Beaurepaire Rohan, João Francisco da Silva Lisboa, Domingos José Gonçalves de Magalhães, Antônio Henriques Leal. A principal razão das contendas desencadeadas com a publicação da primeira edição da História geral do Brasil de Varnhagen, segundo os autores que analisam o autor, foi o tratamento dispensado ao indígena.

No conjunto geral da obra, Varnhagen buscou entrelaçar coerência e legitimidade nas ações dos colonizadores portugueses dos tempos coloniais como fundamentos para compor um determinado ideal de nacionalidade, articulando, como se viu, a cidadania de poucos e a escravidão de muitos, buscando os caminhos para o progresso da civilização brasileira. Essa história da nação brasileira, com efeito, tem como fio condutor a história da sua civilização. Nesse processo, Varnhagen aposta na colonização portuguesa da América como salvaguarda do Estado e como meio de civilizar a população. Em relação ao indígena não será diferente. $\mathrm{O}$ autor, em primeiro lugar, ressalta a catequese como possibilidade de civilizar os gentios, para, depois, apontar a tutela como a única possibilidade de resgatar os índios do "estado natural de selvageria". Em relação à civilização do indígena, Varnhagen manteve-se irredutível, de tal sorte que chegou a propor a restauração das bandeiras para capturar os indígenas, acirrando os ânimos de seus contendores.

Em 1867, Varnhagen respondeu às críticas que lhe fizera João Francisco Lisboa, afirmando que a "civilização dos índios, ponto que considero vital para o nosso progresso e desenvolvimento nacional [...]" só poderia ocorrer através do uso da força, pois seria "impossível colonizar pacificamente o atual império". ${ }^{35}$ Seus contemporâneos revidaram com veemência o argumento, do uso da força, de Varnhagen. Manuel Antônio de Almeida utilizou, inclusive, um argumento muito caro ao Visconde, na tentativa de persuadi-lo: a civilização dos letrados e o uso da razão. Para Almeida, "por meio da razão o homem deve

\footnotetext{
${ }^{33}$ Francisco Adolfo Varnhagen. História geral do Brasil antes de sua separação e independência de Portugal. Belo Horizonte/São Paulo: Itatiaia/Edusp, 10ª edição integral, vol. 3, tomo V, p. 26.

${ }^{34}$ Veja-se a esse respeito: Lúcia Maria Pachoal Guimarães, op. cit.; Manoel Luiz Salgado Guimarães, op.cit.; Temístocles Cezar, op.cit.; Nilo Odália, op.cit.; Bernardo Ricupero, op.cit.; Wilson Martins, op.cit.; Antonio Cândido, op.cit.

${ }^{35}$ Cf. Francisco Adolfo de Varnhagen. Os índios bravos e o Sr. Lisboa, Timon $3^{\circ}$, apostila e nota $G$ aos $n .11$ e 12 do Jornal do Timon, contendo 26 cartas inéditas do jornalista e um extrato do folheto 'Diatribe contra Timonice', etc. Lima: Imprensa Liberal, 1867.
} 
ajudar os mais ignorantes com a sua inteligência". ${ }^{36}$ As polêmicas acerca do indígena ocuparam muito tempo e muita tinta foi gasta pelos beletristas do IHGB. O que importa reter das proposições indianistas de Varnhagen e das polêmicas delas suscitadas é o significado das contendas à época e o que lhe foi atribuído pela historiografia ulterior que versa sobre a obra e o pensamento político do autor, notadamente explicitado no Memorial Orgânico. ${ }^{37}$

Lúcia Paschoal Guimarães afirma que, em 1855, a História Geral do Brasil havia sido encaminhada à Comissão de História do IHGB, para dela receber um parecer. A intenção de Varnhagen era ser apresentado como historiador oficial da agremiação. Não obstante, a autora afirma que a "História geral do Brasil foi simplesmente esquecida...", pois os censores da Comissão encarregados de avaliar a obra, entre eles João Francisco Lisboa, "não se pronunciaram a respeito e nem deram satisfações à Diretoria do IHGB". ${ }^{38}$ Para a autora, não há dúvidas de que as proposições indianistas de Varnhagen tenham sido a principal razão para o isolamento intelectual do autor e a desconfortável posição que passou a ocupar entre os sócios do IHGB, após a publicação da primeira edição de sua obra.

A respeito do isolamento intelectual de Varnhagen, cumpre ressaltar que o relato do autor sobre a revolta baiana de 1798 pode designar outras possibilidades sobre a questão. Bernardo Ricupero sugere um bom caminho ao avançar a proposição de Lúcia Paschoal Guimarães e chamar a atenção para a ameaça que as revoltas provinciais representavam para a unidade nacional e a manutenção da ordem da política do Regresso. Para Bernardo Ricupero, não há dúvida de que o programa político de Varnhagen é basicamente conservador, pois assim como os saquaremas, ${ }^{39}$ para o Visconde "não há força sem união, $e$ não haverá união enquanto não se estabeleça a verdadeira unidade", ${ }^{40}$ Nessa perspectiva, a narrativa das revoltas dos anos finais dos tempos coloniais significava, para os homens de letras do oitocentos, o enfrentamento no plano ideológico de duas questões ameaçadoras para os conservadores da política do Regresso: o localismo das revoltas do final do século XVIII e o espectro republicano das Revoluções Francesa e Haitiana.

Assim, em relação à revolta baiana de 1798, como se viu, não chega a surpreender que o autor tenha utilizado o recurso providencialista, somado às efetivas ações punitivas das autoridades locais sobre os réus dos mais baixos setores daquela sociedade, os únicos "sectários" dos ideais republicanos, para explicar o malogro da referida revolta. Ou seja, a revolta baiana de 1798 é interpretada por Varnhagen como um movimento fadado ao

\footnotetext{
${ }^{36}$ Manuel Antonio de Almeida. Civilização do indígena, duas palavras ao autor do Memorial Orgânico. Correio Mercantil, 13 de dezembro de 1851.

${ }^{37}$ Francisco Adolfo de Varnhagen. Memorial Orgânico. In: Revista Guanabara, tomo I, 1851.

${ }^{38}$ Lúcia Maria Paschoal Guimarães. Debaixo da imediata proteção..., op.cit., p. 213.

39 "Saquarema" é a denominação dada aos políticos conservadores do Império Brasileiro porque um dos líderes conservadores, o Visconde de Itaboraí, tinha uma fazenda em um município de mesmo nome. Cf. MATTOS, Ilmar R. O tempo saquarema. São Paulo: Hucitec, 1999.

${ }^{40}$ Varnhagen, Memorial, op.cit., p. 241.
} 
fracasso, posto que fora protagonizada por homens dos mais baixos setores daquela sociedade, sectários das ideias republicanas.

Contudo, se Varnhagen exprime com maestria o conservadorismo da política do Regresso, ao escrever a História Geral do Brasil seu conservadorismo em relação aos termos da escrita dessa história ganha algumas cores, chegando mesmo a surpreender. Bernardo Ricupero chama a atenção para o fato de que no momento em que Varnhagen escrevia a sua História do Brasil, cerca de 1850, o próprio Visconde de Porto Seguro reconhecia que o "espírito público" das províncias do Norte já estaria bastante desenvolvido. Até porque a Independência do Brasil, segundo o Visconde de Porto Seguro, só foi possível com a presença do "herdeiro da Coroa", que sem agir "não teria levado a cabo esse movimento, organizando-se uma só nação unida e forte, desde o Amazônia até o Rio Grande do Sul" "41 Com efeito, para Bernardo Ricupero, a causa principal do repúdio que sente Varnhagen pelas revoltas coloniais "está no perigo que elas [ideias republicanas] representavam para concretizar o Império americano legado por Portugal, ao fragmentar os país em minúsculas 'Guianas',42

Neste ponto em especial, cabe retomar duas questões em relação à interpretação de Varnhagen sobre a revolta baiana de 1798. O Visconde de Porto Seguro foi o primeiro historiador a descrever o conteúdo dos pasquins, ditos sediciosos pelas autoridades do Tribunal da Relação da Bahia, em 1799. A informação não é de pouca relevância. Primeiro, porque ao descrever minuciosamente os princípios políticos e filosóficos dos partícipes da revolta de 1798, na tentativa de desqualificá-los, relacionando-os às ações dos escravos da Revolução Haitiana, Varnhagen acaba tocando em duas questões delicadas do projeto político do Regresso conservador: o regionalismo e o republicanismo. Considerando que a política regressista objetivava, antes de mais nada, alcançar a "ordem pública", contando sobretudo com o apoio das elites provinciais, a descrição do conteúdo veiculado dos pasquins serviu, no plano ideológico, como um programa político de viés republicano que poderia obstaculizar o projeto conservador de contar com a adesão política dos liberais moderados e exaltados das províncias. Depois, mesmo com a intenção de reafirmar os homens de "ínfima qualidade" daquela sociedade como os únicos entusiastas das ideias republicanas, ao descrever o conteúdo dos pasquins, Varnhagen confere relevância ao movimento que até então era tido por irrelevante.

Manuel Salgado Guimarães, fundamentando-se nas proposições de Jörn Rüsen, demonstra que no processo de escrita da história nacional, no século XIX, a transição da passagem do tempo, do passado para o presente, não foi um processo natural, i. e., a transição emergiu de um processo social e coletivo que transformou, em um primeiro momento, a

\footnotetext{
41 Francisco Adolfo de Varnhagen. A história da Independência do Brasil. Belo Horizonte/São Paulo: Itatiaia/Edusp, $7^{\mathrm{a}}$ edição, revisão e notas de Hélio Vianna, p. 259.

${ }^{42}$ Bernardo Ricupero, op.cit., p. 143
} 
experiência da passagem do tempo em "passado", para, em um segundo momento, transformar esse passado em história, ${ }^{43}$ Ainda que o objetivo de Varnhagen fosse desqualificar social e politicamente o evento em tela, a revolta baiana de 1798 passou a compor a narrativa pátria oitocentista sobre o passado colonial da nação brasileira.

O mais importante, contudo, é que a descrição dos pasquins, na interpretação de Varnhagen, fez com que a revolta baiana de 1798 adquirisse relevância, destoando da própria interpretação que o autor elabora sobre a Independência do Brasil, em 1822, uma vez que ao expressar os princípios políticos e filosóficos dos homens de "ínfima qualidade" o autor sugere um movimento pensado, elaborado e projetado, mesmo que malogrado, a partir de um conteúdo normativo de bases republicanas. Ou seja, ao deixar "falar a verdade dos documentos", pois para Varnhagen "a verdade é uma só, e há de triunfar em vista dos documentos que vão aparecendo", ${ }^{4}$ o Visconde de Porto Seguro demonstra, no plano simbólico, a capacidade de articulação política de um setor que ainda fazia muito barulho durante o oitocentos e, não à toa, foi a grande preocupação dos arautos da política do segundo Reinado nos quadros do IHGB.

Neste sentido, tudo leva a crer que no processo de composição dos fatos, elaboração e escrita da história pátria, em relação à revolta baiana de 1798, a ideia de verdade histórica do autor se sobrepôs às orientações políticas com as quais a história do Brasil deveria ser escrita a partir de uma documentação bastante constrangedora para o acervo da Casa da Memória Nacional, ${ }^{45}$ A esse respeito, Lúcia Paschoal Guimarães demonstra o destino melancólico de um manuscrito de Caetano Pinto de Miranda Montenegro, relativo à Revolução Pernambucana de 1817, encaminhado à Comissão de História do IHGB, em 1839, para que fosse julgado o mérito e a conveniência da divulgação. A Comissão recusouo, sob a alegação de que a publicação do manuscrito comprometeria as pessoas ainda vivas, e recomendou que o documento fosse guardado nos arquivos do Instituto até que todas as pessoas mencionadas comparecessem perante o tribunal da posteridade. ${ }^{46}$

Ocorre que a documentação que foi entregue pelo Conde de Palma, os pasquins elaborados pelos partícipes da revolta de 1798, não foi submetida à Comissão de História do IHGB. Varnhagen, nesse caso, caminhou na contramão dos termos da política historiográfica da agremiação, sobre o que se podia dar a dizer e o que se deveria silenciar na interpretação dos tempos coloniais para, ao fim e ao cabo, compor a história da nação brasileira do século XIX. É por essas e outras, talvez mais por situações como essa do que pelas polêmicas em relação ao índio, que Varnhagen amargou grande indiferença entre seus pares, sócios efetivos do Instituto Histórico e Geográfico Brasileiro, revertida apenas com a publicação

\footnotetext{
${ }^{43}$ Cf. Manuel Luís Salgado Guimarães. Repensando os domínios de Clio: angústia e ansiedades de uma disciplina. Revista Catarinense de História. Florianópolis, n. 5, 1998, pp. 5-20.

${ }^{44}$ Francisco Adolfo de Varnhagen. Op. cit.

${ }^{45}$ Expressão de Lúcia Maria Paschoal Guimarães.

${ }^{46}$ Lúcia Maria Paschoal Guimarães. O tribunal da posteridade. Op.cit., p. 33-34.
} 
do necrológio que lhe dedicou Capistrano de Abreu, em 1878. ${ }^{47}$ Considerando, como demonstra Lúcia Paschoal Guimarães, que "o Imperador D. Pedro II, inclusive, parecia incentivar a polêmica indianista ..., ${ }^{48}$ caberia saber se essas contendas não encobriram ou serviram para desviar a atenção sobre as questões relativas ao republicanismo que nunca deixou de ameaçar a hegemonia política e social do Regresso conservador e, depois, do Partido Conservador, durante o Segundo Reinado.

A esse respeito cumpre ainda destacar o impacto da publicação da primeira edição e as várias alterações feitas por Varnhagen para a segunda edição que foi publicada em 1871. Dos historiadores que se ocuparam com a repercussão da primeira edição da obra de Varnhagen e das alterações feitas para a segunda edição, a maioria é unânime em afirmar que houve da parte do Visconde de Porto Seguro a tentativa de explicar, e até amenizar, sua posição inicial em relação aos índios. ${ }^{49}$ Todavia, as alterações feitas na interpretação da revolta baiana de 1798, em particular, e as revoltas coloniais do final do XVIII e início do XIX, no geral, pouca atenção mereceram. Para a segunda edição, Varnhagen, em primeiro lugar, retirou os termos "socialista e plebiscitos", que enunciavam o tema da revolta a ser abordado, e inseriu, como se viu, o comentário onde ressalta a atuação de d. Fernando José de Portugal e Castro na punição exemplar dos réus enforcados em praça pública.

Depois, o autor cortou integralmente o conteúdo dos pasquins veiculado na primeira edição, que explicitava os termos políticos e filosóficos dos partícipes, sem fazer qualquer referência à referida documentação, na segunda edição. Neste ponto em especial, tudo leva a crer que as críticas e as polêmicas nas quais o historiador se envolveu não eram apenas sobre os indígenas, até porque não parece ser por outra razão que Varnhagen tenha escrito sobre as alterações a serem feitas para a publicação da segunda edição, no canto direito da página 292, da primeira edição, em tom de desabafo:

"[...] e sobretudo dos documentos [ilegível] delles q aqui incluiremos (sic). Se são verdadeiros pasquins, nem por isso se devam desprezar, qdo. são elles tão próprios para dar uma exacta idéia da importância dos revolucionários". 50

\footnotetext{
${ }^{47} \mathrm{O}$ Necrológio de Francisco Adolfo de Varnhagen, Visconde de Porto Seguro, foi publicado no Jornal do Comércio, em 1878, e depois reproduzido em apenso à quarta edição de História Geral do Brasil. Embora Capistrano tenha inserido o artigo do cônego Joaquim Caetano Fernandes Pinheiro na nota de rodapé n. 66 na História Geral do Brasil, de Francisco Adolfo Varnhagen.

${ }^{48}$ Lúcia Maria Paschoal Guimarães, Francisco Adolfo de Varnhagen. História Geral do Brasil. In: Lourenço Dantas Mota (Org.). Um banquete no trópico, op.cit., p. 95.

49 Antonio Candido, op.cit.; Arno Wehling, op.cit.; Bernardo Ricupero, op.cit.; Lucia Maria Paschoal Guimarães, op.cit.; Manoel Luís Salgado Guimarães, op.cit.; Nilo Odália, op.cit.; Temístocles Cezar, op.cit.; Wilson Martins, op.cit.

${ }^{50}$ Cabe ressaltar, ainda, que a observação manuscrita de Varnhagen sobre o conteúdo dos pasquins não foi incorporada nas edições ulteriores da "História Geral do Brasil", pelos anotadores Capistrano de Abreu e Rodolfo Garcia. AHI, doc. cit, p. 292.
} 
DOI: https://dx.doi.org/10.12795/Temas-Americanistas.2021.i47.02

Se para Varnhagen a documentação dos pasquins comprovava a irrelevância dos "revolucionários", a documentação dos Autos das Devassas, base para a escrita da história sobre o movimento, demonstra que foram seis os homens condenados à pena capital pelos desembargadores do Tribunal da Relação da Bahia, em 1799. Considerando que um fugiu e outro teve a pena comutada, ainda assim, para Varnhagen, foram três réus condenados por crime de lesa-majestade, sendo que, apenas no final do item, o autor menciona o réu Manuel Faustino como um dos quatro réus enforcados em praça pública. A informação não encontra paralelo na documentação, mas quando o autor omite o nome de Manuel Faustino do grupo de condenados, ele não aponta uma liderança do movimento entre os homens livres, pobres e pardos.

Não parece ter sido por outra razão que o cônego Joaquim Caetano Fernandes Pinheiro fez questão de criticar duramente a escrita da história da revolta baiana de 1798 na $1^{\text {a }}$ edição da obra de Varnhagen:

Se, como conhece o Sr. Varnhagen, a revolução da Bahia não tinha chefe, ou pelo menos não queria elle manifestar-se, deixando-se até nas mãos da ignorância a redacção dos documentos officiaes, não vemos a necessidade das medidas de extremo rigor à que recorreu o governo portuguez, confirmando a sentença proferida pela relação, que condennava à morte a João de Deus do Nascimento, cabo d"esquadra de milícias, os dous soldados Lucas Dantas e Luiz Gonzaga das Virgens, e o criolo liberto Manoel Faustino, que apenas contava com 18 annos de edade!(BN, Revista Popular, tomo VIII, 1860: 221).

Como se viu, ao descrever as proposições dos partícipes da revolta, veiculadas nos pasquins sediciosos, Varnhagen demonstrou a existência de bases teóricas para as ações dos revoltosos livres e pobres, contrariando a ideia de que o universo da política era restrito à classe senhorial detentores da cidadania política, pois a partir da Constituição de 1824 esses homens podiam votar e serem eleitos. A razão pela qual Francisco Adolpho de Varnhagen excluiu essa informação na segunda edição da obra relaciona-se com a análise sobre a Independência do Brasil circunscrita em 1822 para o autor. Como demonstra Lúcia Paschoal Guimarães, tal como Ranke, Varnhagen "privilegia sobretudo o Estado, daí sua ênfase na primazia dos fatos políticos, relativamente isolados das forças sociais", o que significa que mesmo incorporado o conteúdo dos pasquins sediciosos na primeira edição de sua obra, é inegável a prevalência das ações político-administrativas dos portugueses colonizadores, por mais de três séculos, em uma narrativa cuja lógica histórica era evolutiva e linear. 
DOI: https://dx.doi.org/10.12795/Temas-Americanistas.2021.i47.02

Na segunda edição da obra, publicada em 1873 - no mesmo ano em que Joaquim Norberto publica, nos quadros da agremiação, a primeira obra que versa exclusivamente sobre a Inconfidência Mineira de 1789 -, o que é reforçado na segunda edição da obra de Varnhagen é a Independência do Brasil como o resultado natural da ação colonizadora e civilizadora dos Bragança e das críticas recebidas por homens de letra afinados com o poder político hegemônico. A informação que beira a obviedade nos remete à outra menos evidente: a análise de Varnhagen na segunda edição de sua obra contribuiu significativamente para a integração da Conjuração Baiana de 1798 no conjunto de eventos que compõem a chamada história nacional justamente porque o autor construiu o eixo de significação do evento na repressão bem sucedida dos acusados, no enforcamento seguido de esquartejamento dos corpos de homens livres, pobres e pardos que fizeram política nas ruas da cidade de Salvador.

A permanência da criminalização do exercício político das classes populares nas edições ulteriores da obra de Francisco Adolpho de Varnhagem, com anotações de Capistrano de Abreu e Rodolfo Garcia, resultou nas premissas sobre as quais os historiadores do século XX analisaram a Conjuração Baiana de 1798, e na narrativa veiculada nos livros didáticos distribuídos pelo Estado Brasileiro do Oiapoque ao Chuí até hoje. 